\title{
Detecting vegetation-precipitation feedbacks in mid-Holocene North Africa from two climate models
}

\author{
Y. Wang ${ }^{1, *}$, M. Notaro $^{1}$, Z. Liu ${ }^{1}$, R. Gallimore ${ }^{1}$, S. Levis ${ }^{2}$, and J. E. Kutzbach ${ }^{1}$ \\ ${ }^{1}$ Center for Climatic Research, University of Wisconsin-Madison, 1225 West Dayton Street, Madison, WI 53706, USA \\ ${ }^{2}$ National Center for Atmospheric Research, PO BOX 3000, Boulder, CO 80307, USA \\ * now at: Pacific Northwest National Laboratory, PO BOX 999, MSIN K9-24, Richland, WA 99352, USA
}

Received: 13 July 2007 - Published in Clim. Past Discuss.: 25 July 2007

Revised: 7 February 2008 - Accepted: 10 March 2008 - Published: 31 March 2008

\begin{abstract}
Using two climate-vegetation model simulations from the Fast Ocean Atmosphere Model (FOAM) and the Community Climate System Model (CCSM, version 2), we investigate vegetation-precipitation feedbacks across North Africa during the mid-Holocene. From mid-Holocene snapshot runs of FOAM and CCSM2, we detect a negative feedback at the annual timescale with our statistical analysis. Using the Monte-Carlo bootstrap method, the annual negative feedback is further confirmed to be significant in both simulations. Additional analysis shows that this negative interaction is partially caused by the competition between evaporation and transpiration in North African grasslands. Furthermore, we find the feedbacks decrease with increasing timescales, and change signs from positive to negative at increasing timescales in FOAM. The proposed mechanism for this sign switch is associated with the different persistent timescales of upper and lower soil water contents, and their interactions with vegetation and atmospheric precipitation.
\end{abstract}

\section{Introduction}

Vegetation interactions/feedbacks have received tremendous attention in modern climate (Charney et al., 1975, 1977; Schlesinger et al., 1990; Pielke et al., 1998; Brovkin 2002) and paleoclimate (Kutzbach, 1981; Kutzbach et al., 1996; Ganopolski et al., 1998; Claussen et al., 1999, 2003; Foley et al., 2003; Wang et al., 2005a, b; Wang and Mysak, 2005) studies. Previous understanding (Charney et al., 1975, 1977; Woodward et al., 1998; Box 2-6 in Ruddiman, 2001) largely emphasized that those interactions played an important role in amplifying initial climate perturbations (i.e., positive feedbacks). Using a statistical method (see Liu et al.,

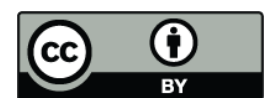

Correspondence to: Y. Wang

(yi.wang@pnl.gov) 2006a, Notaro et al., 2006 for detailed methodology), we present a negative vegetation-precipitation feedback at the annual timescale from two mid-Holocene simulations with FOAM (Gallimore et al., 2005), and CCSM2 (Levis et al., 2004a), both of which are coupled with the Lund-PotsdamJena Dynamic Global Vegetation Model (LPJ-DGVM, Sitch et al., 2003).

In semiarid areas, the dynamics of the simulated hydrologic cycle is partially governed by the interplay between transpiring water in vegetated areas and surface evaporation from bare soils (Dirmeyer, 1994; Sellers et al., 1997). One of the two underlying processes is that when vegetation cover increases, ground evaporation decreases (mainly because there is less energy reaching the soil) and transpiration increases (because there is more vegetation). In our experiments, the imbalance of a large bare ground evaporation over transpiration under fully wet soil conditions in mid-Holocene can produce a local enhancement of rainfall for bare soil condition compared to vegetated condition (i.e., negative feedback). A previous study (Doherty et al., 2000) with the GENESIS climate model (Thompson and Pollard, 1997) detected weak or insignificant vegetation feedback in amplifying precipitation in eastern North Africa. Furthermore, Levis et al. (2004a) also mentioned in their 50-year "6K6V" simulation that there may have been a weak negative precipitation feedback in North Africa. Furthermore, a recent observational study (Wang et al., 2006) detected that at different timescales, the sign of vegetation-precipitation interactions may change with their statistical model. Previous midHolocene studies (Cooperative Holocene Mapping Project (COHMAP), 1988; BIOME 6000, Prentice and Webb, 1998) indicated that soil in mid-Holocene North Africa was wetter and darker than that in pre-industrial and present-day conditions. Vegetation, mainly grassland, extended farther north into the present-day Sahara Desert (Gasse, 2000, 2002). Small and Kurc (2001) find that observed surface albedo is lower under wet conditions in semiarid areas. Under such a

Published by Copernicus Publications on behalf of the European Geosciences Union. 


\section{CCSM2 Mid-Holocene}
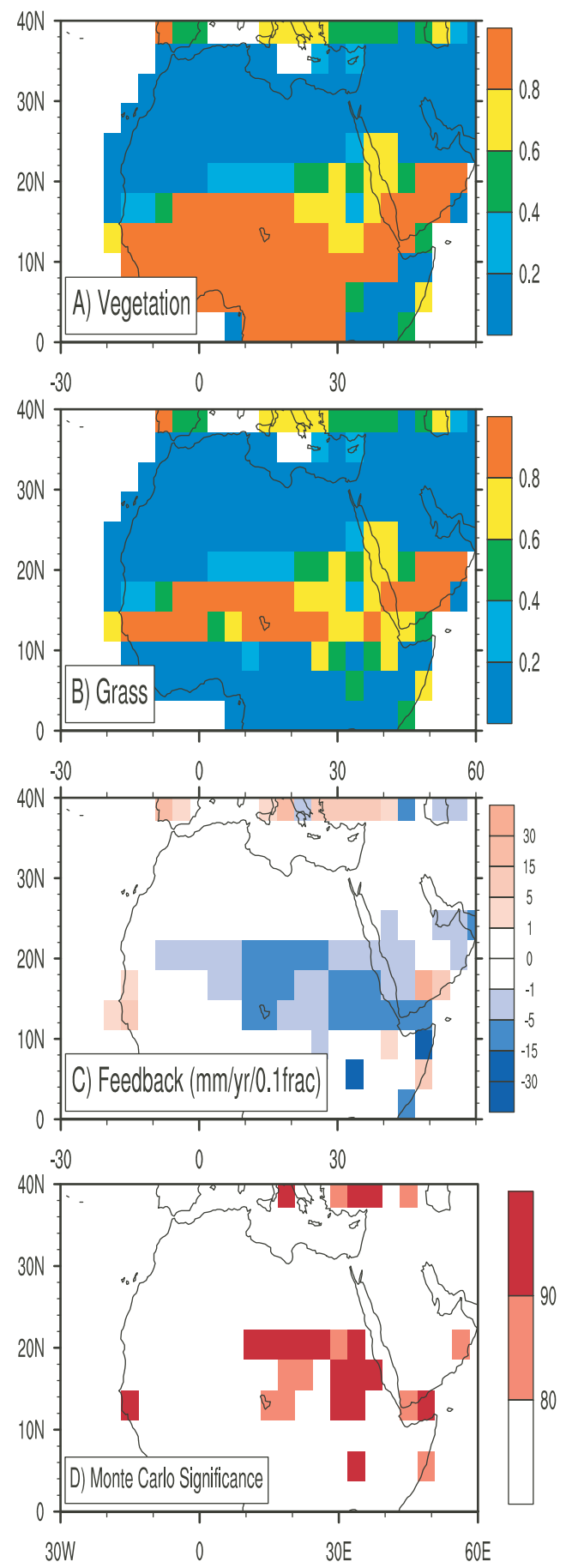

FOAMLPJ Mid-Holocene
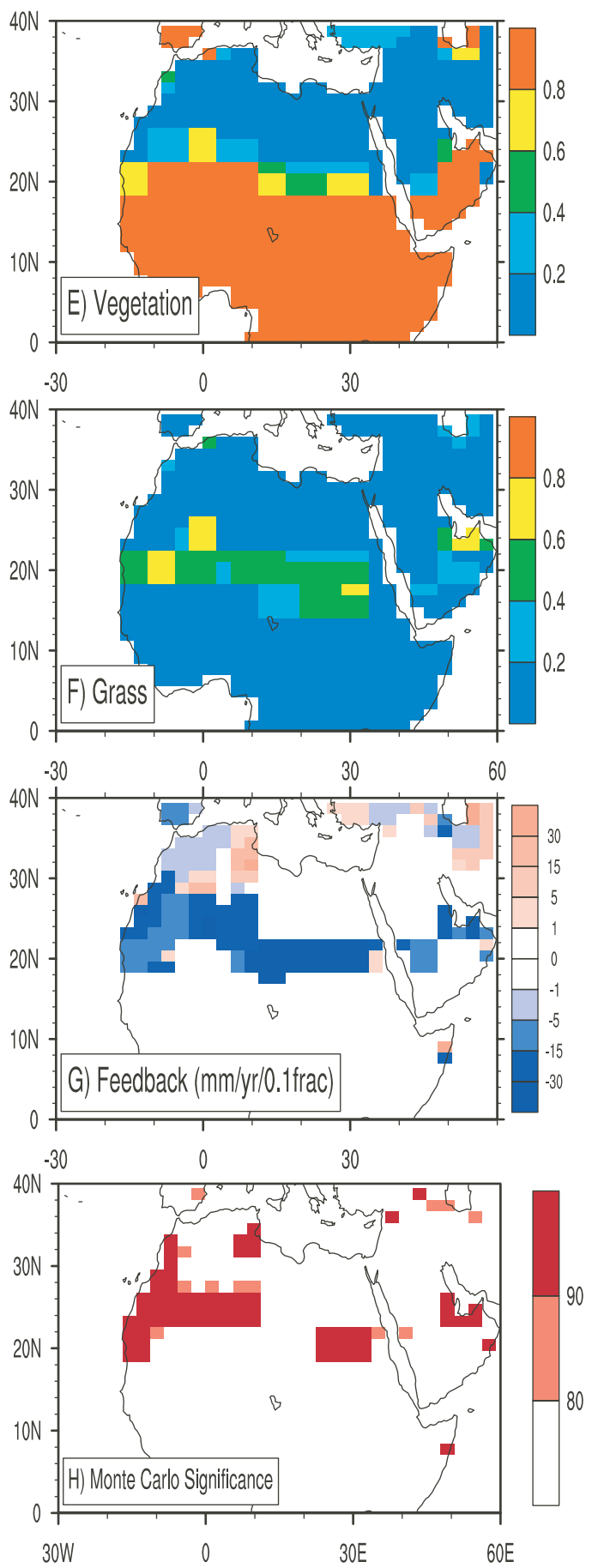

Fig. 1. Mid-Holocene total vegetation fraction for (A) CCSM2 and (E) FOAMLPJ; mid-Holocene grassland coverage for (B) CCSM2 and (F) FOAMLPJ. Estimated feedback parameters (mm/year/0.1 fraction) between total vegetation fraction and annual precipitation (Eq. 2) for (C) CCSM2 and (G) FOAMLPJ mid-Holocene snapshot runs. Statistical (Monte-Carlo) significance of feedback parameters for (D) CCSM2 and (H) FOAMLPJ. In calculating the feedback parameters, we constrain the range of parameter from -60 to $60 \mathrm{~mm} / \mathrm{year} / 0.1 \mathrm{fraction}$. We did this because in cases when the denominator of Eq. (2) becomes small (low vegetation autocorrelation), the estimated feedback parameter becomes a huge, unreliable number. We also use 9-gridcell averaging to smooth the feedback parameters here and in Fig. 2. 
distinct climate background, vegetation feedbacks are quite different than present-day (Liu et al., 2006a).

In the meantime of this research, Notaro et al. (2008) conducted a statistical and dynamical assessment of simulated vegetation-rainfall interactions in mid-Holocene North Africa with foci on the FOAM model. Compared with the study of Notaro et al. (2008), we present here the detailed results from two mid-Holocene equilibrium simulations in fully coupled climate models (FOAM and CCSM2). Our statistical approach is similar to that employed in Notaro et al. (2008). However, we have combined it with an extensive Monte-Carlo bootstrap test in order to assign the statistical significance for our assessment. In addition, our result further expands the findings of Notaro et al. (2008) in that we report the timescale-dependence of the estimated vegetationprecipitation feedbacks, which, to our best knowledge, has not been reported before in vegetation and paleoclimate researches.

\section{Model description, experimental design and outline of methodology}

\subsection{Model description and experimental design}

The coupled atmosphere-ocean component is FOAM version 1.5. The atmosphere module has a horizontal resolution of R 15 ( $4.5^{\circ}$ by $7.5^{\circ}$ latitude-longitude) and 18 vertical levels. The ocean component has a horizontal resolution of $128 \times 128$ and 32 vertical levels. The LPJ module has been synchronously coupled with FOAM (see Gallimore et al., 2005 for more details). The simulated vegetation pattern agrees with satellite observation (Gallimore et al., 2005; Notaro et al., 2005) and other vegetation model simulations (Cramer et al., 2001). The mid-Holocene simulation of CCSM2 (Holland, 2003) consists of a 350-year integration with orbital forcing prescribed at 6000 years before present (hereafter $6 \mathrm{ka})$ with atmospheric $\mathrm{CO} 2$ fixed $(280 \mathrm{ppmv})$, which was extended from the "6K6V" simulation in Levis et al. (2004a). The CCSM2 is a fully coupled atmosphereocean-land surface-vegetation climate model (see Holland, 2003; Levis et al., 2004b for more details), and is run at $\mathrm{T} 31$ ( $3.75^{\circ}$ by $3.75^{\circ}$ latitude-longitude) and 26 vertical levels. The ocean model of CCSM2 has 40 levels in the vertical and a horizontal resolution of $100 \times 116$.

A typical difference between FOAM and CCSM2 is their soil modules. CCSM2 has ten soil layers, while FOAM only has two soil layers. However, the bare ground surface albedo only depends on the top layer soil moisture in our climate models. In CCSM2, soil texture varies by grid cell and with depth (Oleson et al., 2004). The data comes from the IGBP soil dataset (Global Soil Data Task, 2000). Soil colors are from Zeng et al. (2002). The vegetation and soils at $6 \mathrm{~K}$ in CCSM2 tend to have little albedo difference and sometimes in a direction opposite than expected (Levis et al., 2004a).
In FOAM, soil texture is fixed for the period of integration. In substituting the original FOAM land component with the LPJ-based one, we retain the original FOAM CCM2-based surface/soil diffusive temperature calculation scheme that assumes 4-soil layers, but replaces the simple, single layer (bucket) soil water component with the 2-layer soil water scheme of LPJ (Sitch et al., 2003). The local runoff is calculated when the soil water of a layer exceeds water holding capacity, and is used as input to the river routing scheme for freshwater discharge into the oceans. The zonal distribution of average runoff predicted by CCSM2 also compares favorably to a $1^{\circ}$ by $1^{\circ}$ gridded dataset of observed runoff (see Fig. 8 in Stich et al., 2003).

The FOAMLPJ Holocene transient simulation (Liu et al., 2006b; Liu et al., 2007) restarts from the end of the midHolocene snapshot run (see Gallimore et al., 2005 for more details), and is integrated from $6.5 \mathrm{ka}$ to pre-industrial $(0 \mathrm{ka})$ with varying orbital forcing (Berger, 1978) and fixed $\mathrm{CO}_{2}$ $(280 \mathrm{ppmv})$ without flux corrections. This experiment setup allows us to focus on the insolation forcing without considering other external (solar and $\mathrm{CO} 2$ variability) and internal volcano) forcings. In this experiment, we simulate a green Sahara and followed by an abrupt collapse of vegetation (mainly grassland) in Northern Africa region. The vegetation collapse region (Liu et al., 2007) corresponds to the major negative feedback region in Fig. $1 \mathrm{~g}$ of our paper.

\subsubsection{Outline of methodology}

Following the methodology in Frankignoul and Hasselmann (1977), Liu et al. (2006a) and Notaro et al. (2006), atmospheric variables (precipitation, temperature, evapotranspiration etc.) can be divided into two components:

$A\left(t+\delta t_{a}\right)=\lambda_{V} V(t)+N\left(t+\delta t_{a}\right)$

where $A(t)$ represents atmosphere variables at time t, $V(t)$ is vegetation variables at time $\mathrm{t}, \lambda_{V}$ is the feedback parameter, $\delta t_{a}$ is the atmospheric response time, and $N(t)$ is the atmospheric noise from internal atmospheric processes that are independent of vegetation variability. Following the method of Frankignoul et al. (1998), we have:

$\lambda_{V}=\frac{\operatorname{cov}[A(t), V(t-\tau)]}{\operatorname{cov}[V(t), V(t-\tau)]}$

where $\tau$ is the lag time, which is longer than the persistence time of atmospheric internal variability. The feedback parameter $\lambda_{V}$ is calculated as the ratio of lagged covariance between $A$ and $V$ to the lagged covariance of $V$. When calculating the feedback parameter, we employed the weighted average from the first three lags (e.g., one, two and three year lags for annual timescale) with weights of 1.0, 0.5 and 0.25 , respectively.

Furthermore, the statistical significance of $\lambda_{V}$ can be assessed by the Monte Carlo bootstrap approach (Czaja and 
CCSM2 Feedback (mm/year/0.1frac) Ground Evaporation
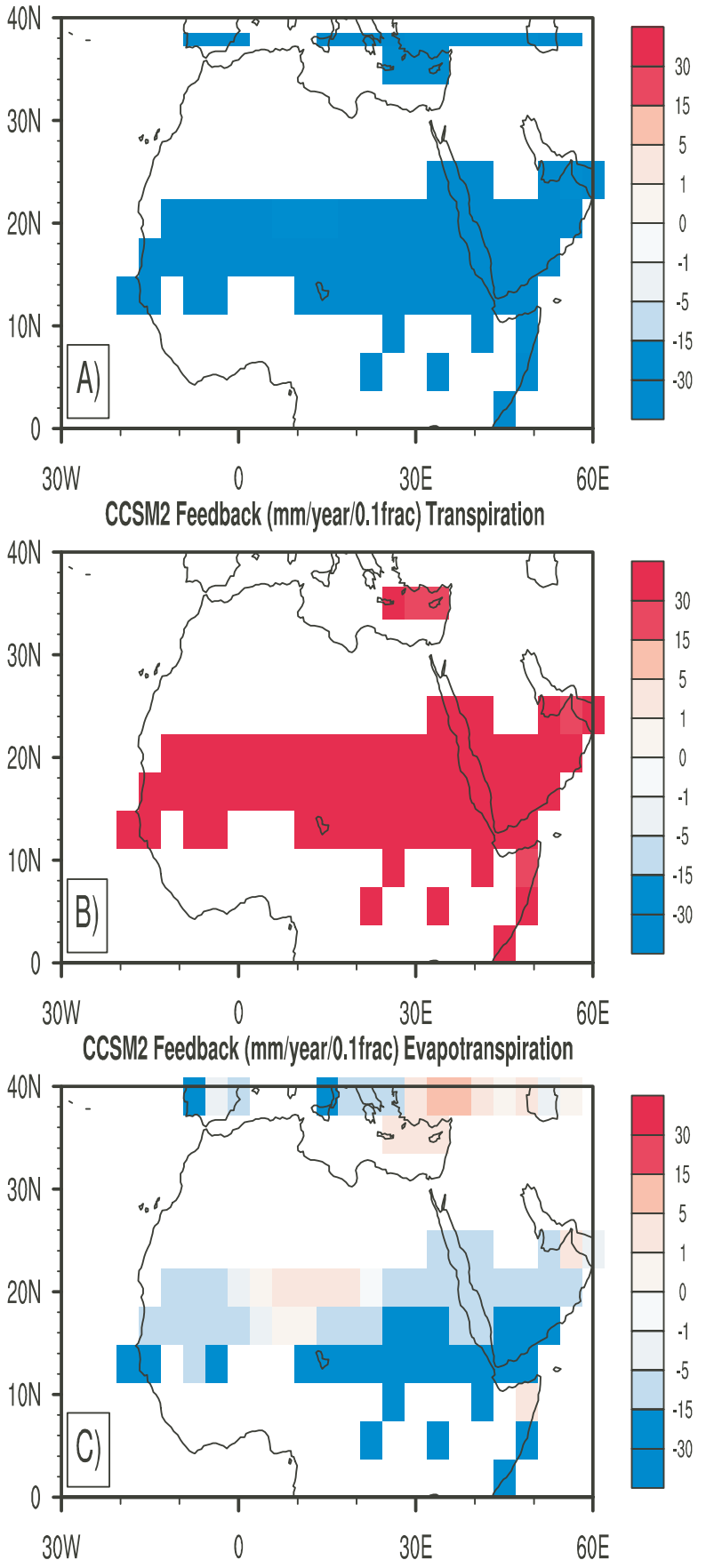

FOAMLPJ Feedback (mm/year/0.1frac) Ground Evaporation

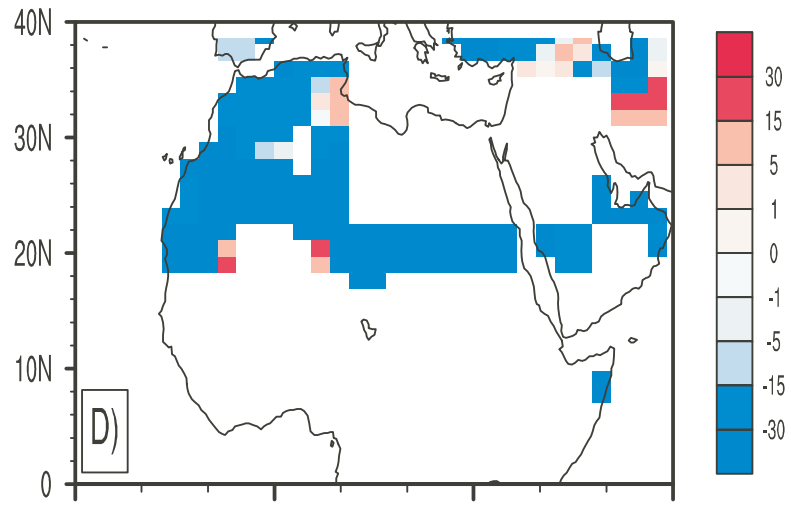

3OW $\quad$ 3OE $\quad$ OOE

FOAMLPJ Feedback (mm/year/0.11rac) Transpiration
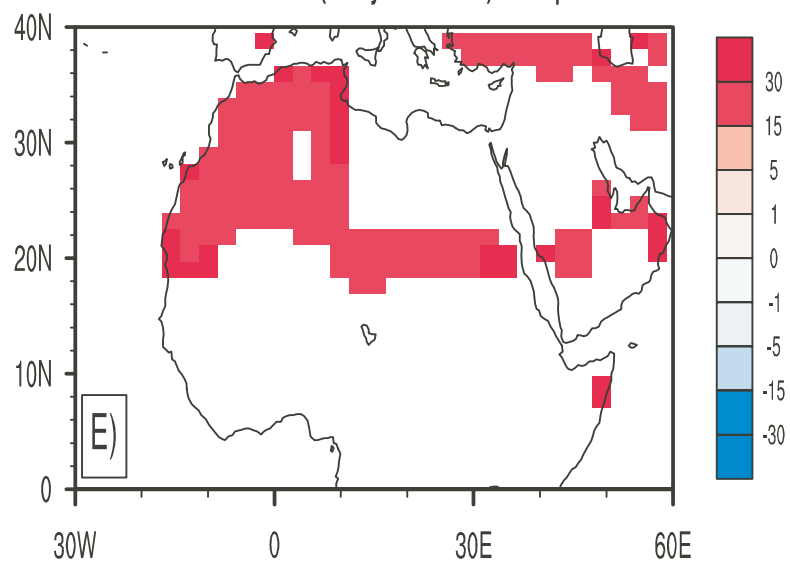

FOAMLPJ Feedback (mm/year/0.1frac) Evapotranspiration

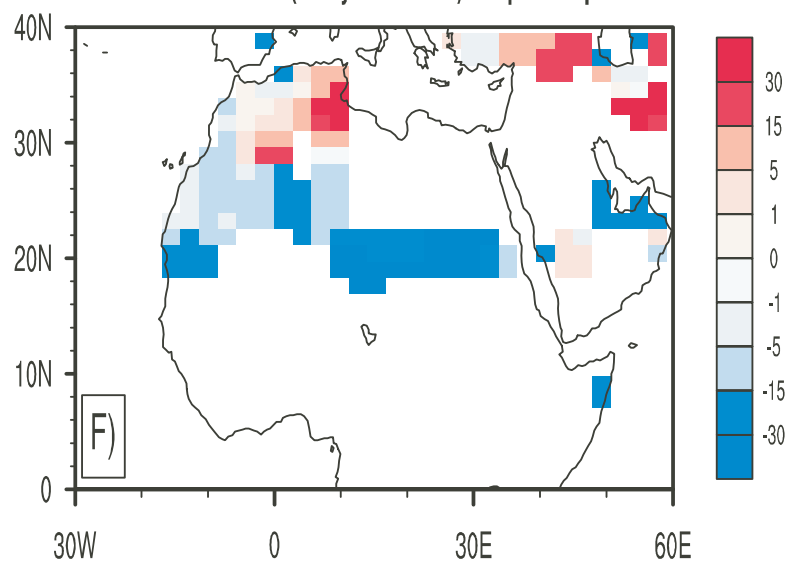

Fig. 2. Estimated feedback (Eq. 2) between total vegetation fraction and ground evaporation (mm/year/0.1 fraction) for (A) CCSM2 and (D) FOAMLPJ from mid-Holocene snapshot runs. Estimated feedback between total vegetation fraction and transpiration (mm/year/0.1 fraction) for (B) CCSM2 and (E) FOAMLPJ from mid-Holocene snapshot runs. Estimated feedback between total vegetation fraction and evapotranspiration (mm/year/0.1 fraction) for (C) CCSM2 and (F) FOAMLPJ from mid-Holocene snapshot runs. Note that, as in Fig. 1, the three leads averaging with same weights is used.

Frankignoul, 2002). $\lambda_{V}$ is computed 1000 times, each using an atmospheric time series derived from a random permutation of the original time series $A_{t}$. The accumulative proba- bility produced is then used to judge the significance of $\lambda_{V}$. 


\section{CCSM2}
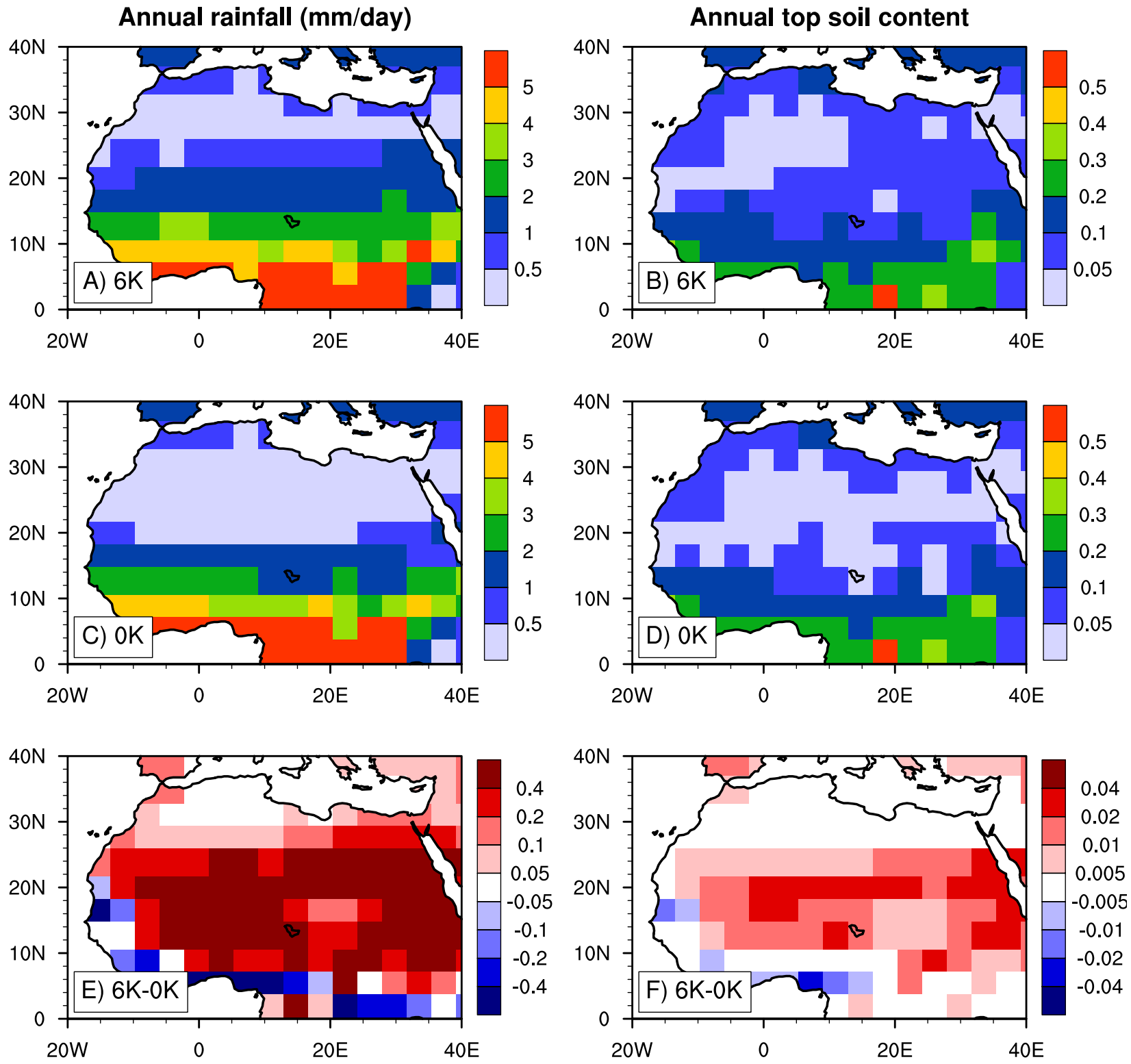

Fig. 3. Annual rainfall (mm/day) for CCSM2 (A) $6 \mathrm{~K}$ control, (C) $0 \mathrm{~K}$ control, and (E) $6 \mathrm{~K}$ minus $0 \mathrm{~K}$. Top soil moisture content $\left(\mathrm{mm}^{3} / \mathrm{mm}^{3}\right.$ ) for CCSM2 (B) 6K control, (D) 0K control, and (F) 6K minus 0K from two sets of 350-year control simulations.

\section{Results}

Following the early work of Frankignoul et al. (1998), the vegetation feedback has been assessed with a simple linear statistical method (Liu et al., 2006a; Notaro et al., 2008). Figure 1 indicates the distribution of total vegetation, grassland and the averaged feedback parameter between total vegetation cover and annual precipitation from CCSM2 and FOAMLPJ mid-Holocene snapshot runs. In the mid-Holocene total vegetation cover, mainly perennial grass- land, has extended farther north into the Sahara region in both models (figures not shown here for vegetation/grassland changes between mid-Holocene and pre-industrial). The negative feedback zone matches well with the grassland area, with a magnitude from 1 to about $15 \mathrm{~mm} /$ year/0.1 fractional coverage for CCSM2, and from 5 to about $30 \mathrm{~mm} /$ year $/ 0.1$ fractional coverage for FOAMLPJ. Overall, CCSM2 indicates a slightly weaker negative feedback than FOAMLPJ, although both are statistically significant (see Fig. 1d and h). To test the statistical significance, we randomly reorganize 


\section{FOAMLPJ}
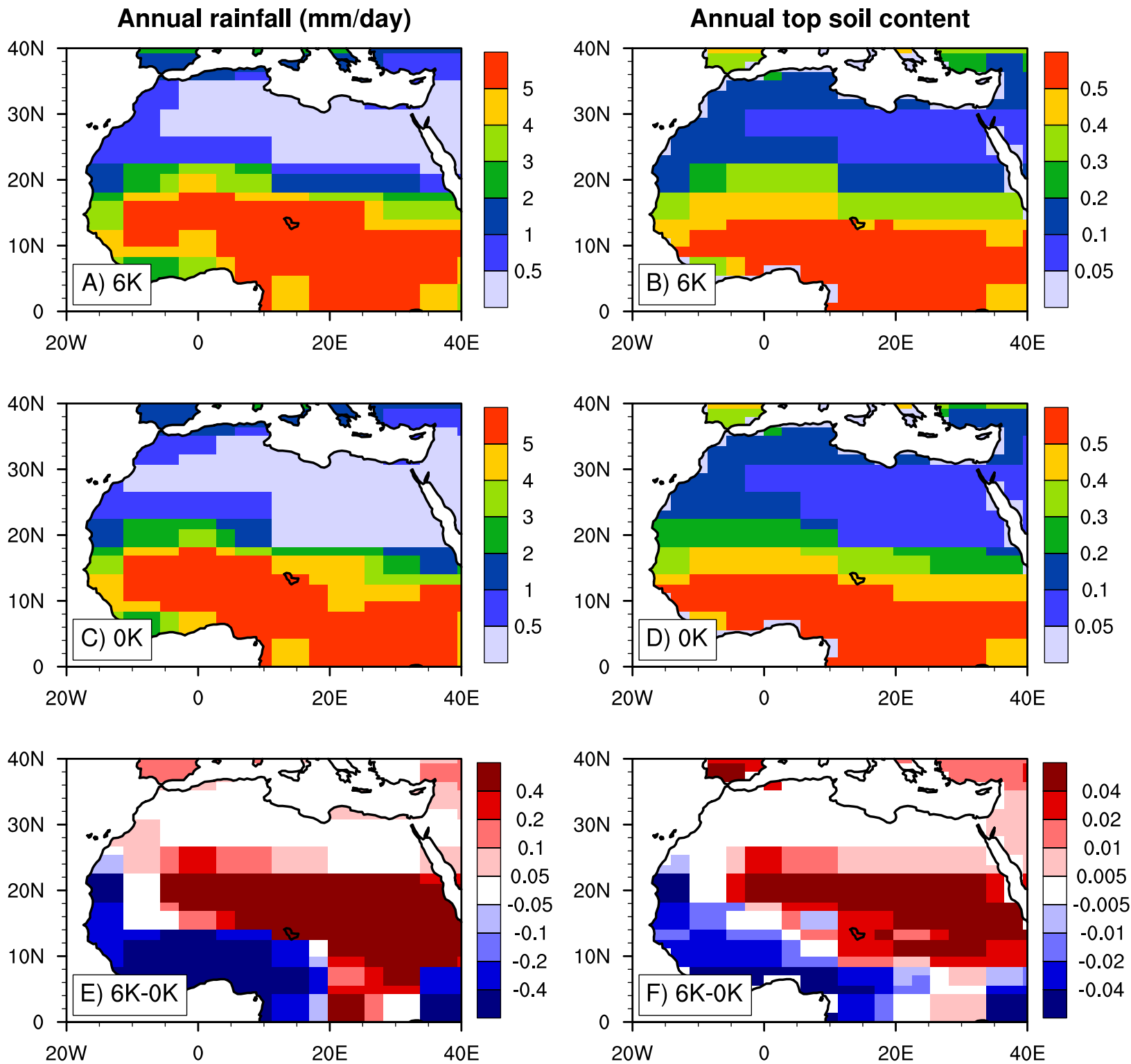

Fig. 4. Annual rainfall (mm/day) for FOAMLPJ (A) $6 \mathrm{~K}$ control, (C) $0 \mathrm{~K}$ control, and (E) $6 \mathrm{~K}$ minus $0 \mathrm{~K}$. Top soil moisture content $\left(\mathrm{mm}^{3} / \mathrm{mm}^{3}\right)$ for FOAMLPJ (B) 6K control, (D) 0K control, and (F) 6K minus 0K from two sets of 400-year control simulations.

the annual precipitation, and create 1000 sets for both simulations. We recalculate the new feedback parameters with randomly-ordered annual precipitation, and compared them with those presented in Fig. 1c and g. With $80 \%$ and $90 \%$ confidence levels, we declare that the negative feedback is of statistical significance in both simulations in the North African semiarid grassland areas.

With a detailed feedback analysis, we find that the main source of negative feedback comes from bare-ground evaporation (Fig. 2). Note that the total moisture flux, namely evapotranspiration, is equal to the sum of bare-ground evaporation and transpiration from vegetated surfaces. The transpiration term is always positively related to vegetation change. However, among other factors, the total moisture flux depends strongly on the competition of bare-ground evaporation and transpiration from vegetated surfaces. In semidry grassland areas, if the soil is wet and dark, as in midHolocene condition, the first term becomes the same/more important as/than the second term, which causes the strong coincidence of grassland and negative feedback area. 
Charney's albedo change theory does not work out here because the albedo change from grassland to wet/dark soil is small in mid-Holocene. Hence the pre-condition of a large surface albedo change from deserted (bare-ground) and vegetated surfaces does not apply. Furthermore, a map of feedback parameters between total vegetation and evapotranspiration (Fig. 2c and f) indicates that the negative feedback mainly caused by the increase of bare-ground evaporation, overcomes the reduction of transpiration. We speculate that this may be partially related to the evaporation from a wetter and darker soil in mid-Holocene climatic conditions. When we analyze pre-industrial snapshot simulations from both CCSM2 (Levis et al., 2004) and FOAMLPJ, the negative feedback almost disappears (figures not shown) when the soil becomes drier and lighter.

In the 6500-year transient simulation of FOAMLPJ, we also capture a similar negative feedback and statistical significance as above (figure not shown). In this transient run, we reproduce a vegetation (mainly grassland) collapse at around 5000 years ago (Liu et al., 2006b; Liu et al., 2007; Notaro et al., 2008), which is in good agreement with the paleoreconstruction work of deMenocal et al. (2000). Accompanying this ecosystem collapse is a gradual decline in annual precipitation (see Fig. 1b and c in Liu et al., 2006b; Fig. 2 in Notaro et al., 2008). If the vegetation had a strong positive feedback on annual precipitation, we would expect a similar abrupt change in precipitation. This feature further confirms our finding of a negative interaction between vegetation and precipitation in North African grasslands in the mid-Holocene.

To show the wetter mid-Holocene conditions in CCSM2 and FOAMLPJ, we obtain the output from two sets of control simulations in both climate models. Figure 3 plots the annual rainfall and top layer soil water content from the CCSM2 mid-Holocene and pre-industrial control runs (350-year average). It is clear that the top soil is wetter in CCSM2 midHolocene run (Fig. 3f). This wetter soil corresponds to a higher rainfall in mid-Holocene than that in pre-industrial (Fig. 3e). Similarly, Fig. 4 shows the same variables for the FOAMLPJ mid-Holocene and pre-industrial control runs (400-year average). For both CCSM2 and FOAMLPJ, the wetter soil and higher rainfall conditions closely correspond to the negative feedback regions (Fig. 1c and g) in midHolocene. It is also interesting to note that the areas of wetter soil and higher rainfall are quite different in CCSM2 and FOAMLPJ. This could most likely explain the different locations of negative feedback zones in Figs. 1 and 2.

However, when analyzing monthly feedback parameters, the two climate vegetation models show slightly different features (Fig. 5). With monthly FPAR (Fraction of Photosynthetically Active Radiation absorbed by vegetation canopy, an indication of greenness for vegetation) and monthly precipitation from FOAMLPJ, we find that the feedback changes sign at different timescales. Notice, in preparation our time series for three-monthly and seasonal feedback analysis, we

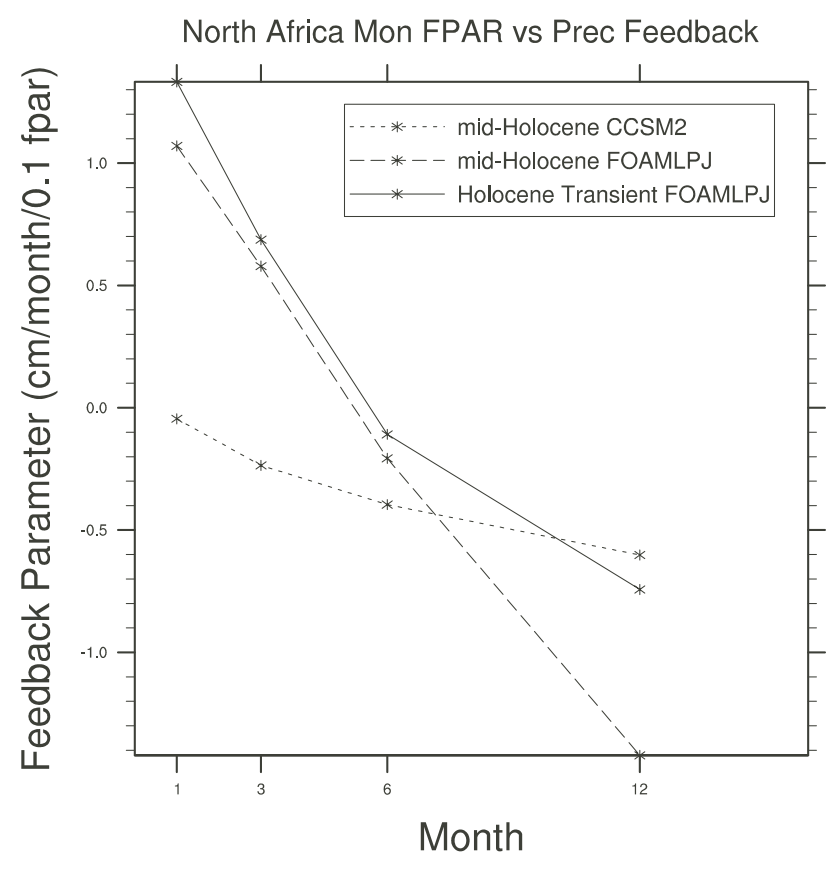

Fig. 5. Area-averaged feedback parameters (18-23 N, 11-36E for FOAMLPJ, 11-22 N, 11-36E for CCSM2), calculated from monthly FPAR and atmospheric precipitation, when we bin individual monthly data into one-month, three-month, six-month, and twelve-month timeseries. Dashed line is for mid-Holocene snapshot run of FOAMLPJ and CCSM2. Solid line is for transient Holocene run from 6000 to 5500 years BP of FOAMLPJ.

combine the individual monthly data into the corresponding time series at three-month and six-month time intervals. At monthly to seasonal time scales, the vegetation (FPAR) has positive feedbacks to atmospheric precipitation at the same timescale, which is indicated by the positive interaction between leaf phenology and precipitation. However, at semiannual and annual timescales, the feedback parameter becomes negative. We speculate that this is partially caused by the interaction between top and lower layer soil water contents, their different persistent times, and effects on atmospheric precipitation. In early spring, a high FPAR in FOAM can induce large transpiration from deep soil water and hence greater precipitation for the following month when the top soil layer is still dry( Notaro et al., 2008). For CCSM2, this sign change feature is not obvious, although it shows a decreasing trend of feedback with increasing timescales as in FOAMLPJ. The less positive vegetation precipitation feedback in North Africa in CCSM2 than in FOAM has also been found in Liu et al. (2006a). We speculate that this is caused by the different soil components in these two climate models as mentioned before. 


\section{Concluding remarks}

We have presented three important findings with two fullycoupled atmosphere-ocean-land surface-vegetation climate model simulations in the mid-Holocene. First, a negative feedback between vegetation and precipitation mainly occurs in the mid-Holocene, when the overall climate and soil are wetter and darker than pre-industrial and present-day conditions. Second, the negative feedback is partially caused by the competition between ground evaporation and transpiration from vegetated surfaces. In the mid-Holocene, the first term has a stronger effect upon moisture fluxes than the second term, although we agree that this may be model dependent. Lastly, at monthly to seasonal timescales, the vegetation precipitation feedback is still positive for FOAM. The feedback changes its sign from positive to negative when moving from monthly and seasonal to semi-annual and annual timescales. This sign change feature is not present in CCSM2, possibly due to different soil module components. However, both climate models have the same decreasing trend of feedback when timescales are increasing.

When the large-scale background climatic conditions change from wetter to drier from the mid-Holocene to preindustrial and/or present-day, the negative feedback almost disappears. This confirms that the background climate is important when studying vegetation climate interactions. The former theory of Charney et al. $(1975,1977)$, based on the large difference of surface albedos between vegetated and desert areas, may only apply to present-day conditions in North Africa because this albedo change is negligible in the mid-Holocene when the soil is wet and dark. Bare ground evaporation is also much weaker than transpiration in modern times due to the dry soil condition. However, in the midHolocene, the bare ground evaporation becomes as important as transpiration. Furthermore, the previous understanding of interactions between vegetation and precipitation may not change at different timescales. As shown in this paper and a recent observational study (Wang et al., 2006), when moving to different timescales, these interactions could be both positive and negative.

Acknowledgements. This work has been supported by ESH/NSF. The CCSM2 and FOAMLPJ model simulations have been carried out at NCAR computation resources. We also would like to thank the two anonymous reviewers and H. Renssen whose input helped to improve the paper. This paper is CCR Contribution Number 922.

Edited by: H. Renssen

\section{References}

Berger, A. L.: Long-term variations of daily insolation and Quaternary climatic changes, J. Atmos. Sci., 35, 2362-2367, 1978.

Brovkin, V.: Climate-vegetation interaction, J. Phys., 4, 57-72, 2002.

Clim. Past, 4, 59-67, 2008
Charney, J. G., Stone, P. H., and Quirk, W. J.: Drought in SaharaBiogeophysical feedback mechanism, Science, 187, 434-435, 1975.

Charney, J. G., Quirk, W. J., Chow, S.-H., and Kornfield, J.: A comparative study of the effects of albedo change on drought in semi-arid regions, J. Atmos. Sci., 34, 1366-1385, 1977.

Claussen, M., Kubatzki, C., Brovkin, V., Ganopolski, A., Hoelzmann, P., and Pachur, H. J.: Simulation of an abrupt change in Saharan vegetation in the mid-Holocene, Geophys. Res. Lett., 24(14), 2037-2040, 1999.

Claussen, M., Brovkin, V., Ganopolski, A., Kubatzki, C., and Petoukhov, V.: Climate change in northern Africa: The past is not the future, Clim. Change, 57(1), 99-118, 2003.

COHMAP Members: Climatic changes of the Last 18,000 years: observations and model simulations, Science, 241, 1043-1052, 1988.

Cramer, W., et al.: Global response of terrestrial ecosystem structure and function to $\mathrm{CO}_{2}$ and climate change: results from six dynamic global vegetation models, Glob. Change Biol., 7, 357373, 2001.

Czaja, A., and Frankignoul, C.: Observed impact of Atlantic SST anomalies on the North Atlantic Oscillation, J. Climate, 15, 606623, 2002.

deMenocal, P., et al.: Abrupt onset and termination of the African Humid Period: Rapid climate response to gradual insolation forcing, Quat. Sci. Rev., 19, 341-361, 2000.

Dirmeyer, P. A.: Vegetation stress as a feedback mechanism in midlatitude drought, J. Climate, 7(10), 1463-1483, 1994.

Doherty, R., Kutzbach, J. E., Foley, J. A., and Pollard, D.: Fully coupled climate/dynamical vegetation model simulations over northern Africa during the mid-Holocene, Clim. Dyn., 16, 561573, 2000.

Foley, J. A., Coe, M. T., Scheffer, M. and Wang, G. L.: Regime shifts in the Sahara and Sahel: Interactions between ecological and climatic systems in northern Africa, Ecosystems, 6, 524539, 2003.

Frankignoul, C., and Hasselmann, K.: Stochastic climate models. Part II: Application to sea surface temperature anomalies and thermocline variability, Tellus, 29, 289-305, 1977.

Frankignoul, C., Czaja, A., and Heveder, B. L.: Air-sea feedback in the North Atlantic and surface boundary conditions for ocean models, J. Climate, 11, 2310-2324, 1998.

Gallimore, R., Jacob, R., and Kutzbach, J. E.: Coupled atmosphereocean-vegetation simulations for modern and mid-Holocene climates: role of extratropical vegetation cover feedbacks, Clim. Dyn., 25, 755-776, doi:10.1007/s00382-005-0054-z, 2005.

Ganopolski, A., Kubatzki, C., Claussen, M., Brovkin, V., and Petoukhov, V.: The influence of vegetation-atmosphere-ocean interaction on climate during the Mid-Holocene, Science, 280, 1916-1919, 1998.

Gasse, F.: Hydrological changes in the African tropics since the Last Glacial Maximum, Quat. Sci. Rev., 19, 189-211, 2000.

Gasse, F.: Diatom-inferred salinity and carbonate oxygen isotopes in Holocene waterbodies of the western Sahara and Sahel (Africa), Quat. Sci. Rev., 21, 737-767, 2002.

Global Soil Data Task. 2000. Global Soil Data Products CD-ROM (IGBP-DIS). CD-ROM. International Geosphere-Biosphere Programme, Data and Information System, Potsdam, Germany (available online at http://www.daac.ornl.gov), 2000. 
Harrison, S. P., Kutzbach, J. E., Liu, Z. Bartlein, P. J., Otto-Bliesner, B., Muhs, D., Prentice, I. C., Thompson, R.: Mid-Holocene climates of the Americas: a dynamical response to changed seasonality, Clim. Dyn., 20, 663-688, 2003.

Holland, M.: The North Atlantic Oscillation-Arctic Oscillation in the CCSM2 and its influence on arctic climate variability, J. Climate, 16, 2767-2781, 2003.

Kutzbach, J. E.: Monsoon climate of the Early Holocene: Climate experiment with the Earth's orbital parameters for 9000 years ago, Science, 214, 59-61, 1981.

Kutzbach, J. E., Bonan, G., Foley, J., and Harrison, S. P.: Vegetation and soil feedbacks on the response of the African monsoon to orbital forcing in the early to middle Holocene, Nature, 384, 623-626, 1996.

Levis, S., Bonan, G., and Bonfils, C.: Soil feedback drives the midHolocene North African monsoon northward in fully coupled CCSM2 simulaitons with a dynamic vegetation model, Clim. Dyn., 23, 791-802, doi:10:1007/s00382-004-0477-y, 2004.

Levis, S., Bonan, G., Vertenstein M., and Oleson, K. W.: The Community Land Model's dynamic global vegetation model (CLMDGVM): Technical description and user's guide. NCAR Technical Note, NCAR/TN-459+IA, 2004.

Liu, Z., Notaro, M., Kutzbach, J. E., and Liu, N.: Assessing global vegetation-climate feedbacks from observations, J. Climate, 19, 787-814, 2006a.

Liu, Z., Wang, Y., Gallimore, R., Notaro, M., and Prentice, I. C.: On the cause of abrupt vegetation collapse in north africa during the Holocene: Climate variability vs. vegetation feedback, Geophys. Res. Lett., 33, L22, 709, doi:10.1029/2006GL028062, 2006 b.

Liu, Z., Wang, Y., et al.: Simulating the transient evolution and abrupt channge of Northern Africa atmosphere-ocean-terrestrial ecosystem in the Holocene, Quaternary Science Reviews, 26, 1818-1837, 2007.

Notaro, M., Liu, Z., Gallimore, R., Vavrus, S. J., Kutzbach, J. E., Prentice, I. C., and Jacob, R. L.: Simulated and observed preindustrial to modern vegetation and climate changes, J. Climate, 18, 3650-3671, 2005.

Notaro, M., Liu, Z., and Williams, J. W.: Observed vegetationclimate feedbacks in the United States, J. Climate, 19, 763-786, 2006.

Notaro, M., Wang, Y., Liu, Z., Gallimore, R., and Levis, S.: Combined statistical and dynamical assessment of simulated vegetation-rainfall interactions in North African during the Mid-Holocene, Global Change Biology, 14, 347-368, doi:10.1111/j.1365-2486.2007.01495.x, 2008.

Oleson, K. W., et al.: Technical Description of the Community Land Model (CLM). NCAR technical note, NCAR/TN461+STR, 2004.

Pielke, R., et al.: Interactions between the atmosphere and terrestrial ecosystems: Influence on weather and climate, Glob. Change Biol., 4, 461-475, 1998.
Prentice, I. C., and Webb, T.: BIOME 6000: reconstructing global mid-Holocene vegetation patterns from palaeoecological records, J. Biogeogr., 25, 997-1005, 1998.

Ruddiman, W. F.: Earth's Climate: Past and Future, W. H. Freeman and Company, New York, NY 10010, USA, 2001.

Schlesinger, W. H., et al.: Biological feedbacks in global desertification, Science, 247(4946), 1043-1048, 1990.

Sellers, P. J., et al.: Modeling the exchanges of energy, water, and carbon between continents and the atmosphere, Science, 275, 502-509, 1997.

Sitch, S., et al.: Evaluation of ecosystem dynamics, plant geography and terrestrial carbon cycling in the LPJ Dynamic Global Vegetation Model, Global Change Biology, 9, 161-185, doi:10.1046/j.1365-2486.2003.00569.x, 2003.

Small, E. E., and Kurc, S.: The influence of soil moisture on the surface energy balance in semiarid environments, New Mexico Water Resource Research Institute Technical Completion Report, No. 318, 2001

Thompson, S. L., and Pollard, D.: Greenland and antarctic mass balances for present and doubled atmospheric $\mathrm{CO}_{2}$ from the GENESIS version 2 global climate model, J. Climate, 10, 871900, 1997.

Wang, W., et al.: Feedbacks of vegetation on summertime climate veriability over the North American Grasslands. Part I: Statistical Analysis, Earth Interactions, 10, 1-27, doi:10.1175/EI196.1, 2006.

Wang, Y., Mysak, L. A., Wang, Z., and Brovkin, V.: The Greening of the McGill Paleoclimate Model. Part II: Simulation of Holocene Millennial-Scale Natural Climate Changes, Clim. Dyn., 24(5), 481-496, doi:10.1007/s00382-004-0516-8, 2005a.

Wang, Y., Mysak, L. A., and Roulet, N. T.: (2005b), Holocene climate and carbon cycle dynamics: Experiments with the "green" McGill Paleoclimate Model, Global Biogeochemical Cycles, 19, GB3022, doi:10.1029/2005GB002484, 2005b.

Wang, Y. and Mysak, L. A.: Response of the ocean, climate and terrestrial carbon to Holocene freshwater discharge after 8 kyr BP, Geophysical Research Letters, 32, L15705, doi:10.1029/2005GL023344, 2005.

Woodward, F. I., Lomas, M. R., and Betts, R. A.: Vegetationclimate feedbacks in a greenhouse world., Philosophical Transactions of the Royal Society of London Series B, 353, 29-38, 1998.

Zeng, X., Shaikh, M., Dai, Y., Dickinson, R.E., and Mineni, R.: Coupling of the common land model to the NCAR community climate model, J. Climate, 15, 1832-1854, 2002. 